\title{
Welcome from the Director of the Graham Sustainability Institute
}

\author{
Volume 1, Fall 2013
}

DOI: http://dx.doi.org/10.3998/mjs.12333712.0001.001

\section{Dear Reader,}

It is with great enthusiasm that I welcome you to the inaugural issue of the Michigan Journal of Sustainability. The Graham Sustainability Institute at the University of Michigan is proud to sponsor this journal because it fills an important and underserved niche-translating high quality research into actionable outcomes across disciplines, fields, and stakeholders.

Some of the best ideas in academia come from the fresh perspectives of young, aspiring scholars. This journal has been created by such individuals-a dedicated and talented group of Graham Doctoral Fellows. Selected from a wide range of schools, colleges, and disciplines, in fields as disparate as sociology and chemical engineering, these Fellows are dedicated to communicating across disciplines and maintaining a focus on larger, multidimensional sustainability challenges.

Drawing on their experiences, discussions, and observations, these Fellows identified a major gap in their fields - a lack of outlets to communicate across academic disciplines and with practitioners in the "real world". In communicating with one another about their research, the Fellows recognized that academic findings are often readable only by other academics in the same field, thus limiting the potential for actionable outcomes. They also recognized that cross-disciplinary conversations are unusual, highly valuable, and critically important in addressing key sustainability challenges. Therefore, it became clear to them that translation, both of words and ideas, is essential for effectively communicating across disciplines and audiences, and that disseminating information in a jargon free format is critical to put sustainability research into practice.

The Michigan Journal of Sustainability not only fills a key gap in academic publishing, but as Andy Hoffman discusses in this issue's opening article, the journal also fosters academics as Honest Brokers, communicating research that contributes to public and political debate. This aligns perfectly with the Graham Institute's translational knowledge mission to pursue sustainability solutions by engaging 
stakeholders and synthesizing data and information to infuse science into real-world decisions that protect the environment and enhance quality of life for present and future generations.

I hope you enjoy this first issue of the Michigan Journal of Sustainability-both the journal and the exceptional young scholars who created it should continue to inspire us for many years to come.

Don Scavia

Graham Family Professor and Director, Graham Institute Special Counsel to the U-M President for Sustainability

Professor, School of Natural Resources \& Environment

Professor, Civil and Environmental Engineering 